\title{
A reassessment of sensory evoked potential parameters in multiple sclerosis: a discriminant analysis approach
}

\author{
G I O VA N I A B B R UZZESE, LEONARDO COCITO, \\ S A N D R O RATTO, M ICHELE AB B R UZZESE, \\ M A S S M O LEANDRI, A N E I LIO F A A LE \\ From the Department of Neurology, University of Genoa, Italy
}

SUMMARY The sensitivity of the different parameters (absolute latency, interwave latency, latency asymmetry, amplitude) of both cervical and cerebral responses evoked by stimulation of the median nerve at the wrist was assessed in patients with multiple sclerosis by discriminant analysis. The peak latency of $\mathrm{N}_{13}$ or $\mathrm{N}_{20}$ SEP components or both was found to be more sensitive than their amplitude, provided that a preliminary covariation with the height of the subjects was performed. The measurement of latency asymmetry between the two sides increased the test's sensitivity, while amplitude asymmetry turned out to be of little diagnostic value. A linear discriminant function with four variates (that is mean amplitude, mean latency, latency asymmetry and height of the subject) was computed to summarise the information provided by the different parameters to give a rapid and exact method for the assessment of SEP abnormalities in multiple sclerosis patients.

The somatosensory evoked potentials (SEPs) are used as an electrophysiological test in patients suspected of multiple sclerosis, particularly when clinical findings are insufficient to settle the diagnosis. It is assumed that SEP abnormalities may be attributed to changes or slowing of conduction through multiple sclerosis plaques, even if asymptomatic. Both the cervical response and the primary cortical response usually have been studied, since they may reflect lesions of the spinal cord and brain white matter, the commonest sites of multiple sclerosis plaques.

Different parameters have been taken into account to judge SEP abnormalities. In addition to waveform distortion (that is absence of components consistently recorded in normal subjects), a prolonged latency or a reduced amplitude or both have usually been considered as pathological, but only a few authors have considered peak latency asymmetry between components evoked by both left and right peripheral nerve stimula-

Address for reprint requests: Giovanni Abbruzzese MD, Clinica Neurologica, Via De Toni 5, I 16132 Genova, Italy.

Accepted 3 October 1980 tion $^{1-3}$ or amplitude asymmetry. ${ }^{4}$ Moreover, different standards $(1 \cdot 0-1.5 \mu \mathrm{V}$ for amplitude, 2.5 or 3.0 standard deviations for latency and latency asymmetry) have been used, and a preliminary latency adjustment for arm length or height of the subjects has not always been performed. ${ }^{5}$ As a result the reported percentages of SEP abnormalities in multiple sclerosis patients have varied.

The aim of the present study was to revise the clinical application of SEPs in multiple sclerosis, identifying the real sensitivity of each parameter (that is its confidence limits in a normal population), and to try to summarise the information provided by the different parameters measured by means of discriminant analysis.

\section{Material and methods}

Observations were performed in 25 patients (15 females and 10 males, mean age 32 years; mean height $166 \mathrm{~cm}$ ) with clinically definite multiple sclerosis ${ }^{6}$, and in 20 normal volunteers (10 females and 10 males, mean age 32 years, mean height $168 \mathrm{~cm}$ ). In all the subjects the cortical and cervical somatosensory potentials evoked by separate stimulation of both left and right median nerve at the wrist were recorded. The 
stimulus intensity was three times thumb motor threshold. Cerebral responses were led off from an active electrode placed on the hand projection area with a midfrontal reference electrode (fig 1, right). Concurrent cervical responses were obtained from an active electrode placed between the second and the third cervical spines and the same reference electrode (fig 1, left). Usually 512 responses were summated. Stimulation, recording and averaging techniques have been extensively described eleswhere. ${ }^{7}$

The following parameters were investigated: amplitude and latency of the main negative peak $\left(\mathrm{N}_{13}\right)$ of the cervical response and of the first main negative peak $\left(\mathrm{N}_{20}\right)$ of the cortical response (fig 1). In both cases amplitude was measured with reference to the base line. Amplitude values of both sides were at first submitted to a log transformation, and for each subject the mean of the left and right $\log$ values was considered (corresponding to the $\log$ of the geometric mean). Amplitude mean values of normals and multiple sclerosis patients were statistically compared by a simple $t$-test. Amplitudes for left and right side stimulation were not processed separately, since a relatively large asymmetry was observed even in nor-

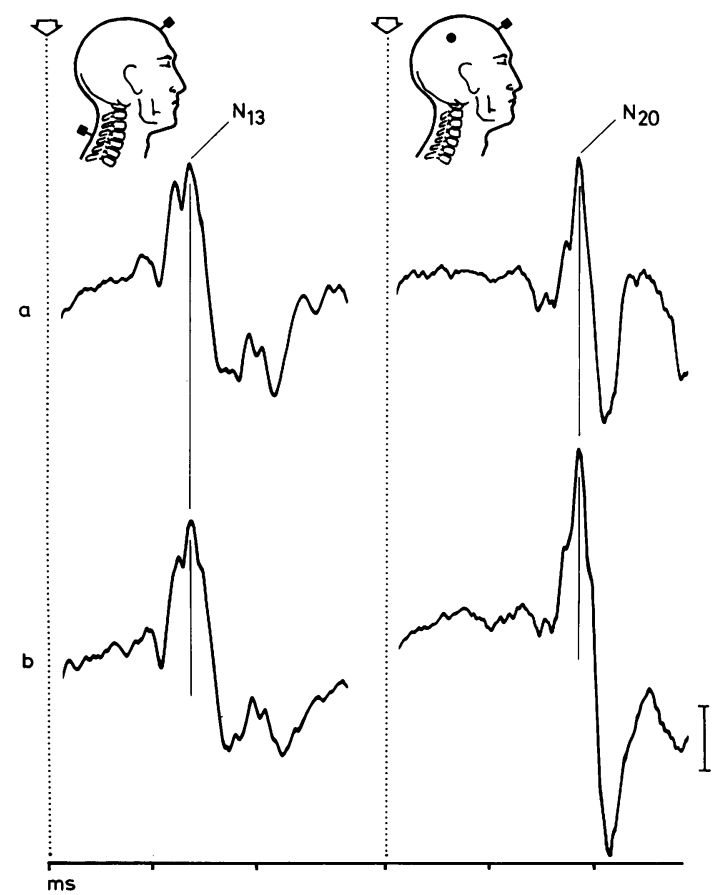

Fig 1 Cervical (left) and cortical (right) SEPs to right $(a)$ and left $(b)$ median nerve stimulation at the wrist in a normal subject. A clear-cut asymmetry of $N_{20}$ amplitude is shown. Electrode placements are drawn in the upper part of the figure. Calibration: $1 \mu V$. mal subjects, the difference between the two sides being over $30 \%$ in eight subjects for either cervical and/or cortical response (fig 1). Latencies were processed through multivariate tests, ${ }^{8}$ which allowed account to be taken not only of single absolute values for both sides but also of their correlation within each subject. The main advantage of this method is also that the information provided by asymmetry between the two sides can be analysed. A comparison between latency values of normals and multiple sclerosis patients was made by a multivariate analysis of covariance $^{8}$ in order to remove the obvious effect of the length of the pathway on conduction time.

On the assumption that our normal sample may be considered as representative of the whole normal population, a $95 \%$ confidence bivariate ellipse ${ }^{9}$ of height-covariated latency values was drawn for $\mathrm{N}_{13}$ and $\mathrm{N}_{20}$. The location of multiple sclerosis patients values with respect to the boundary of the ellipse was assessed, and subjects could accordingly be classified as follows: (1) subjects represented by points which are inside the ellipse ("normal", that is more than $5 \%$ of normal subjects have values even more distant from the centre of the ellipse, representing the mean) (fig 2A), (2) subjects represented by points which are outside the ellipse (and therefore "pathological") because their abscissa (that is left side value) (fig $2 \mathrm{~B}_{1}$ ), ordinate (that is right side value) (fig $2 \mathrm{~B}_{2}$ ) or both

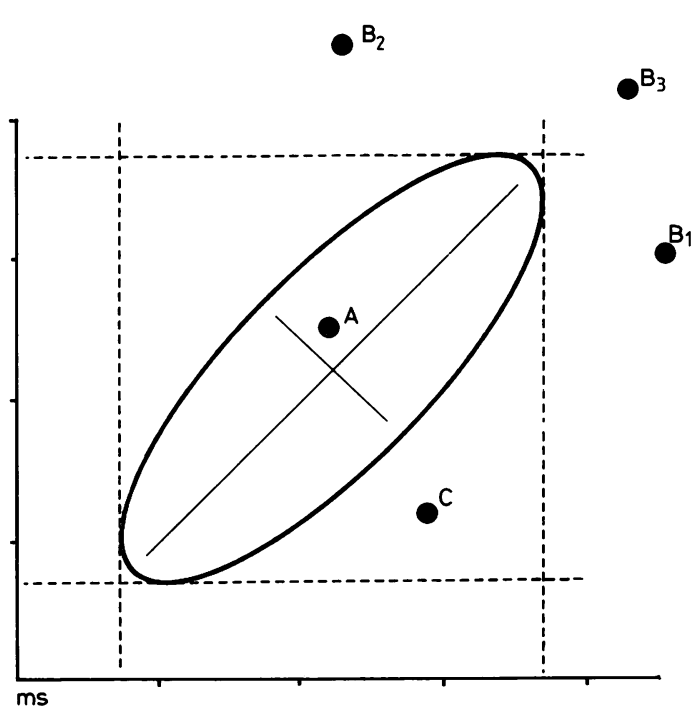

Fig 2 Graphical representation to show the possible locations of MS patients' latency values with respect to $95 \%$ confidence bivariate ellipse of normal subjects. Point $A$, inside the ellipse, indicates a normal value; points $B$ represent subjects pathological for one coordinate ( $B_{1}$ for abscissa, $B_{2}$ for ordinate) or for both $\left(B_{3}\right)$; point $C$ is pathological for asymmetry since it is outside the ellipse, although neither coordinate exceeds the individual confidence limits. 
(fig $2 \mathrm{~B}_{3}$ ) exceed the simultaneous $95 \%$ confidence limits for each variate. The latter are geometrically represented by the tangents to the ellipse parallel to axes, (3) subjects represented by points which are outside the ellipse although neither coordinate, considered per se, exceeds $95 \%$ simultaneous confidence limits: in these subjects asymmetry between left and right side is too large with respect to the distance from the centre of the ellipse (that is the mean for normals). These subjects have been referred to as "pathological for asymmetry" (fig 2C). Figure 3 shows that the "critical" asymmetry does depend on the location of the points. In fact the latter may be outside the ellipse (for example B and D) although the difference between abscissa and ordinate is equal to or even less than that of an inside point (compare $B$ with $\mathrm{A}$ and $\mathrm{D}$ with $\mathrm{C}$ ).

In order to summarise the information provided by the different parameters, a linear discriminant function was computed separately for $\mathrm{N}_{13}$ and $\mathrm{N}_{20}$ taking four variates into account, namely mean amplitude, mean latency, latency asymmetry between the two sides, and height of the subjects. ${ }^{10}$ An attempt to establish some correlation between evoked potentials findings and clinical features of multiple sclerosis patients, according to the "disability rating scale."11 was made by contingency table analysis.

\section{Results}

In five out of 25 multiple sclerosis patients the evoked responses proved to be so modified in waveform as to prevent correct evaluation of both latency and amplitude of the components under investigation.

The results observed in the group of multiple sclerosis patients were summarised in the table.

A. Cervical response Comparison between multiple sclerosis patients and controls showed statistically significant differences for both $\mathrm{N}_{13}$ latency $(\mathrm{F}=$ $3.969, \mathrm{p}<0.05)$ and amplitude $(t=4.521$, $\mathrm{p}<0.001)$.

Figure 4 (left side) shows that in 10 patients the $\mathrm{N}_{13}$ latency of both sides was "normal," while seven patients showed a "pathological" latency either bilaterally (three cases) or unilaterally (four cases); three subjects were only "pathological for asymmetry."

The $\mathrm{N}_{13}$ amplitude was altered (that is below the lower one-tailed confidence limit at $5 \%$ ) in 10 patients and only one of them was "normal" for latency or latency asymmetry or both.

The linear discriminant function was: $Y=$ $-6.9 X_{1}-0.6265 X_{2}+1.724 X_{3}+0.0188 X_{4}, X_{1}$ being the mean $\log$ amplitude $(\mu \mathrm{V}), \mathrm{X}_{2}$ the mean latency (ms), $X_{3}$ the latency asymmetry (ms) and $X_{4}$ the height $(\mathrm{cm}) . Y$ values greater than thres- hold value $(-1 \cdot 272)$ were considered pathological; therefore 17 out of 20 multiple sclerosis patients were likely to be "pathological" according to the discriminant function, although six of them did not present modifications of $\mathrm{N}_{13}$ latency and/or amplitude.

B. Cortical response Comparison between multiple sclerosis patients and controls showed statistically significant differences for both $\mathrm{N}_{20}$ latency $(\mathrm{F}=$ $7 \cdot 220, \mathrm{p}<0.005)$ and amplitude $(t=2 \cdot 767$, $\mathrm{p}<0.01$ ).

Figure 4 (right side) shows that only five patients had a "normal" $\mathrm{N}_{20}$ latency in both sides, while 12 patients had "pathological" latency values, either bilaterally (seven cases) or unilaterally (five cases); two subjects were only "pathological" for asymmetry.

The $\mathrm{N}_{20}$ amplitude was altered in four patients, but all of them had also some latency modifications.

The linear discriminant function for $\mathrm{N}_{20}$ was: $Y=-0.787 \quad X_{1}+0.574 \quad X_{2}+1.173 \quad X_{3}-0.0683 \quad X_{4}$ and the threshold value was: $-0 \cdot 612$. Accordingly 17 out of 20 multiple sclerosis patients were likely to be "pathological," though three of them were completely "normal" for latency or amplitude values or both.

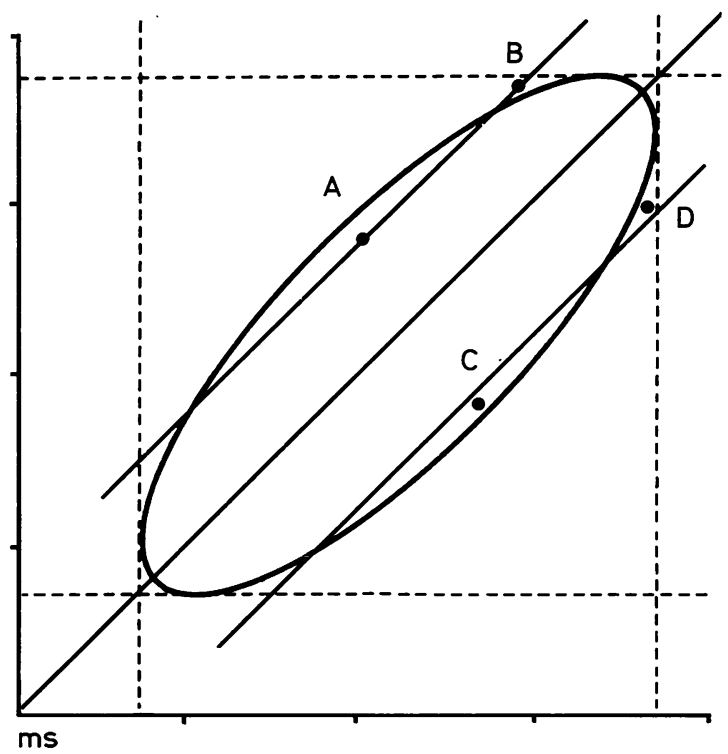

Fig 3 Graphical representation to show that "critical" asymmetry does depend on the location of the point. Points $B$ and $D$ are pathological for asymmetry although the difference between abscissa and ordinate is respectively equal to or less than that of an inside point (compare $B$ with $A$ and $D$ with $C$ ). 


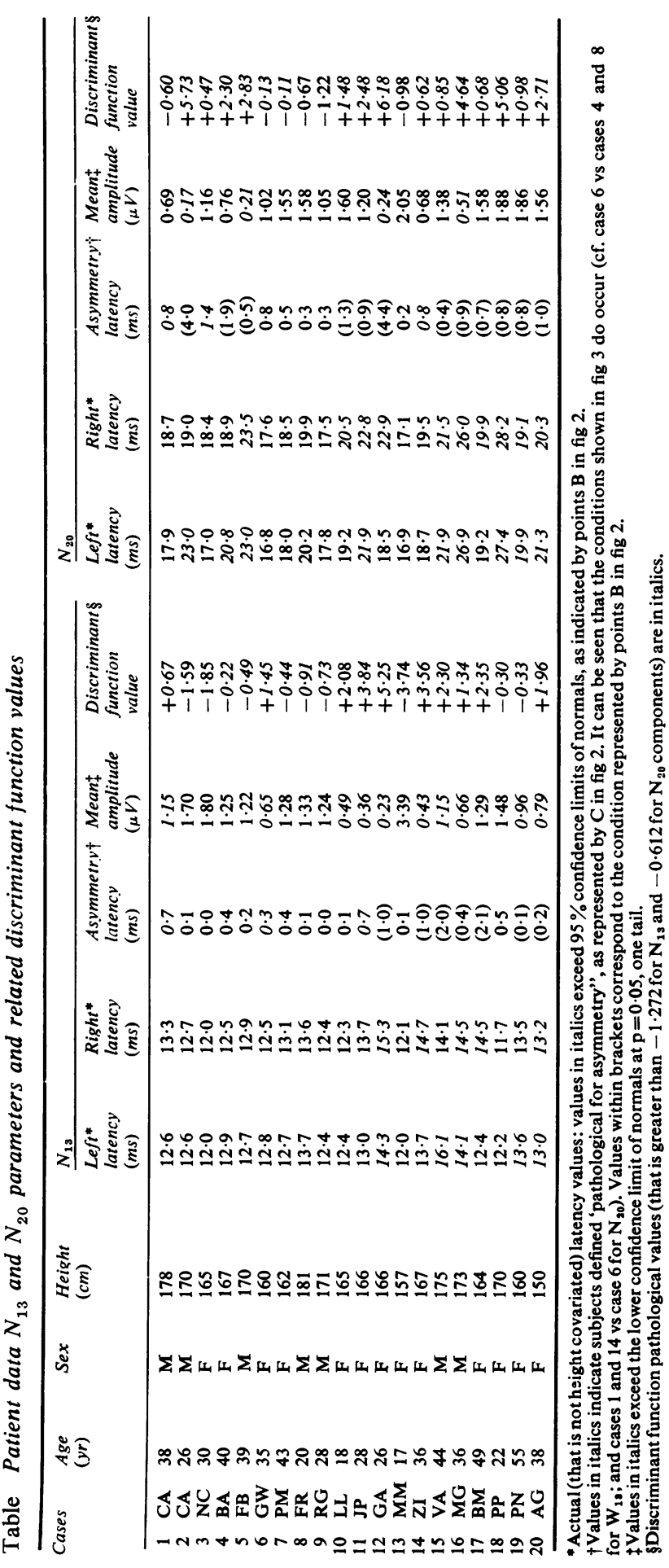




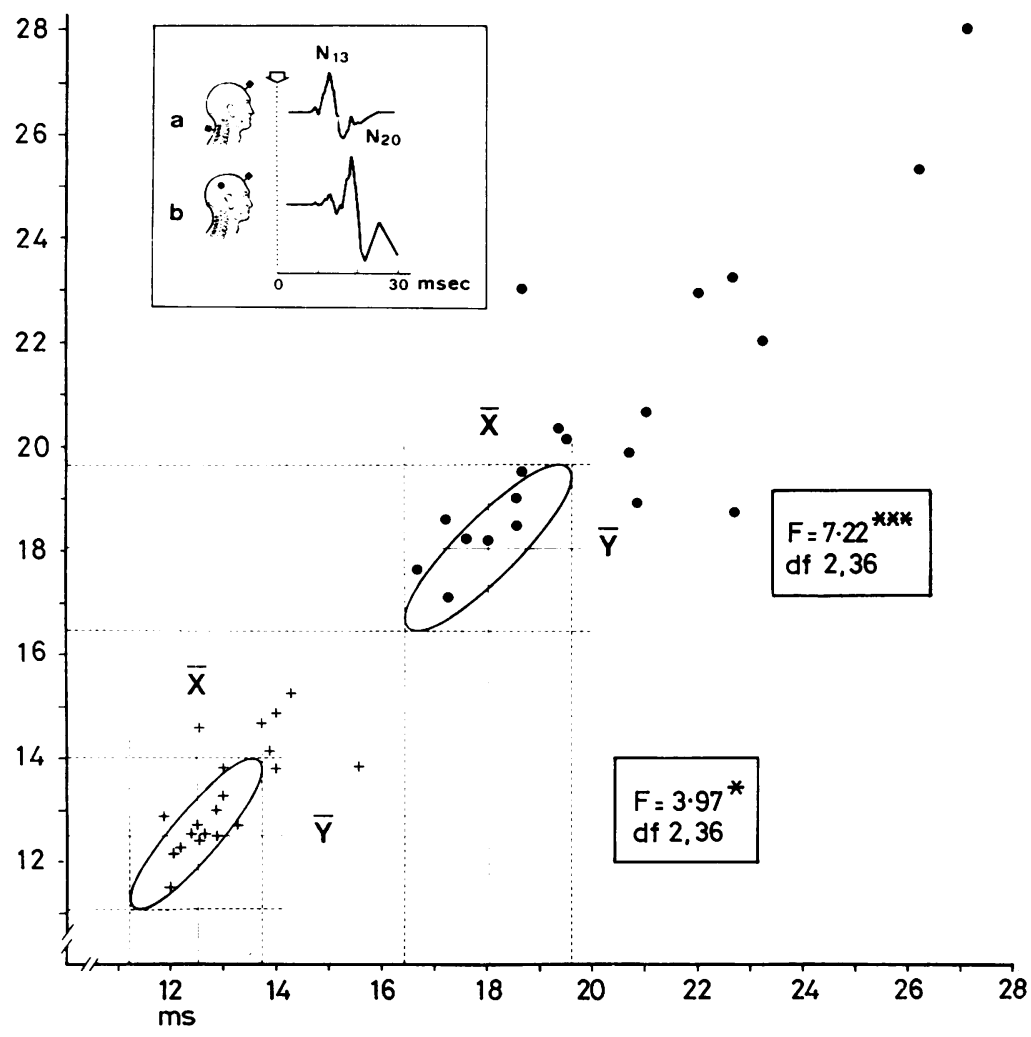

Fig 4 To show the location of $N_{13}$ (crosses) and $N_{20}$ (dots) latency values in multiple sclerosis patients, upon left (abscissa) and right (ordinate) median nerve stimulation, with respect to the $95 \%$ confidence bivariate ellipse of the corresponding normal values. The respective $F$ values are shown in the inserts. Electrode placements and components are indicated in the upper part of the figure.

No correlation was found between electrophysiological results and clinical findings (pyramidal, cerebellar and brainstem symptoms or objective sensory changes). It should be pointed out, however, that the correlation between abnormalities of either $\mathrm{N}_{13}$ or $\mathrm{N}_{20}$ components of the evoked response and the proprioceptive sensibility impairment was nearly significant $\left(\chi^{2}=3 \cdot 402\right.$, $\mathrm{p}=0.065$ ).

\section{Discussion}

The discrepancy of previous studies on SEPs in multiple sclerosis patients rests largely upon the different parameters considered, but some methodological inaccuracies should be pointed out. The latency of SEP components is related to the lemniscal pathway length. Therefore, unlike Trojaborg and Petersen ${ }^{5}$ and (with regard to the careful response) Eisen et $a l,{ }^{1}$ the peak latency values should first be covariated with the height or the arm length of the subjects. Small et al ${ }^{12}$ calculated the regression line of both sides to- gether, but in this way the possibility of detecting a latency asymmetry obviously was lost.

In the present study peak-latency values of both $\mathrm{N}_{13}$ and $\mathrm{N}_{20}$ SEP components were assessed separately, by taking into account at the same time unilateral latency changes as well as possible asymmetry between the two sides, only when the respective absolute latency values were normal. It is not surprising, therefore, that the incidence of latency asymmetry in our study was relatively low (three out of 20 cases for either $\mathrm{N}_{13}$ and/or $\mathrm{N}_{20}$ ), as compared to the results of Lehmann et $a l^{2}$; these authors probably regarded the left-to-right latency difference, even in case of pathological absolute values. Eisen et $a l^{1}$ did not consider the peak-latency increase as a useful parameter and Anziska et $a l^{4}$ disregarded it, evaluating the interwave latency between several components, which was altered in 13 out of 26 subjects. In fact, not all these peaks can be easily detected.

We have studied the $\mathrm{N}_{13}-\mathrm{N}_{20}$ interwave latency in the present group of patients ${ }^{13}$ and found a similar percentage of abnormalities (11 out of 20 
cases). Unlike Eisen and Odusote ${ }^{3}$ we observed a significant side-to-side difference of the $\mathrm{N}_{13}-\mathrm{N}_{20}$ interwave latency only in $10 \%$ of cases. According to our results, however, the $\mathrm{N}_{13}-\mathrm{N}_{20}$ interwave latency, though useful for a rapid screening test as it is unrelated to the height of the subjects, ${ }^{4} 1415$ does not allow all possible information to be gathered. Thus three subjects $(1,14$ and 19) showed a normal $\mathrm{N}_{13}-\mathrm{N}_{20}$ interwave latency, whereas $\mathrm{N}_{13}$ and/or $\mathrm{N}_{20}$ absolute latency values or their degree of asymmetry were pathological. In any case, the $\mathrm{N}_{13}-\mathrm{N}_{20}$ interwave latency fails to reveal any possible increase of the $\mathrm{N}_{13}$ latency, which is likely to occur in multiple sclerosis patients (seven subjects in our study). In addition, a statistically subliminal increase of $\mathrm{N}_{13}-\mathrm{N}_{20}$ interwave latency might produce an abnormal $\mathrm{N}_{20}$ latency, when the $\mathrm{N}_{13}$ absolute latency value approaches the upper limit of normal. Our results may be summed up as showing that the $\mathrm{N}_{20}$ covariated latency is more sensitive than the $\mathrm{N}_{13}{ }^{-}$ $\mathrm{N}_{20}$ interwave latency, thus suggesting that the former parameter is worth considering.

In the previous studies the amplitude of SEP components was generally found to be more sensitive than the latency. ${ }^{12}$ This was not confirmed by our results: the amplitude was reduced in four cases for the $\mathrm{N}_{20}$ component and in 11 cases for the $\mathrm{N}_{13}$ component, but only one subject has no concomitant latency abnormalities.

It should be pointed out that unlike Anziska et $a l^{4}$ we did not evaluate the amplitude asymmetry between the two sides, since a large asymmetry was often observed even in the control group. On the other hand, we submitted the mean amplitude values to a log-transformation, since these values are not arranged in a normal curve. The same procedure is usually accepted in evaluating the peripheral nerve potential amplitude. ${ }^{16}$ These methodological considerations, howevir, cannot account for the different sensitivity observed for the amplitude, which, particularly in the case of $\mathrm{N}_{20}$ component, did not seem to be of great use when considered alone.

The results obtained by computing a linear discriminant function continued the usefulness of the parameters considered, since 17 out of 20 subjects could be exactly classified for either $\mathrm{N}_{13}$ or $\mathrm{N}_{20}$ components. Unlike previous observations, ${ }^{112}$ both the cervical and the cerebral responses seem to share the same sensitivity. Moreover, it should be pointed out, that the discriminant function was altered even in several subjects in which the single parameters were within the normal range, thus indicating that this method is most suitable in the evaluation of borderline values. The abnormalites of both SEP components were not related to the clinical findings or to the degree of disability. As previously reported, ${ }^{1}$ however, the incidence of objective sensory deficits was high $(76 \%)$ in those patients with SEP abnormalities.

We conclude that (1) the peak-latency is more sensitive than the amplitude (particularly in the case of the cerebral response), provided that a preliminary covariation with the height of the subjects is performed, (2) the measurement of the latency asymmetry increases the test's sensitivity, (3) the disseminated nature of the disease is equally reflected by both the cerebral and the cervical responses, (4) using a linear discriminant function may represent a rapid but quite exact method for the assessment of SEP abnormalities in multiple sclerosis patients.

\section{References}

1 Eisen A, Stewart J, Nudleman K, Cosgrove JBR. Short-latency somato-sensory responses in multiple sclerosis. Neurology (Minneap) 1979; 29:827-34.

2 Lehmann D, Gabathuler U, Baumgartner G. Right/left differences of median nerve evoked scalp potentials in multiple sclerosis. J Neurol 1979; 221:15-24.

3 Eisen A, Odusote K. Central and peripheral conduction times in multiple sclerosis. Electroenceph Clin Neurophysiol 1980; 48:253-65.

4 Anziska B, Cracco RQ, Cook AW, Feld EW. Somatosensory far field potentials: studies in normal subjects and patients with multiple sclerosis. Electroenceph Clin Neurophysiol 1979; 45:602-10.

5 Trojaborg W, Petersen E. Visual and somatosensory evoked cortical potentials in multiple sclerosis. J Neurol Neurosurg Psychiatry 1979; 42:323-30.

6 McDonald WI, Halliday AM. Diagnosis and classification of multiple sclerosis. Br Med Bull 1977; 33:4-8.

7 Abbruzzese M, Favale E, Leandri M, Ratto S. Spinal components of the cerebral somatosensory evoked response in normal man: the "S wave". Acta Neurol Scand 1978; 58:213-20.

8 Morrison DF. Multivariate statistical methods. New York: McGraw-Hill, 1976.

9 Documenta Geigy Tables scientifiques. Basel: Geigy SA, 1963.

10 Maccaccaro GA. Le funzioni discriminanti. In: Lison L ed. Statistica applicata alla biologia sperimentale. Milano: Ambrosiana 1961; 313-29.

11 Kurtzke JF. Further notes on disability evaluation in multiple sclerosis with scale modifications. Neurology (Minneap) 1965; 15:654-61.

12 Small DG, Matthews WB, Small M. The cervical somatosensory evoked potential (SEP) in the diag- 
nosis of multiple sclerosis. J Neurol Sci 1978; 35: 211-24.

13 Abbruzzese G, Abbruzzese M, Favale E, Ivaldi M, Leandri M, Ratto S. Il tempo di conduzione del segmento encefalico della via lemniscale nella sclerosi multipla. Riv ital elettroencef neurofisiol 1980; (in press).

14 Abbruzzese M, Favale E, Leandri M, Ratto S. Electrophysiological assessment of the central lemniscal pathway in man. Experientia 1979; 35: $775-6$.

15 Abbruzzese G, Abbruzzese M, Cocito L, Favale $E$, Leandri M, Ratto S. Conduction time of the lemniscal pathway in males and females. Acta neurol scand 1980; 64:132-6.

16 Nielsen VK. Sensory and motor nerve conduction in the median nerve in normal subjects. Acta med scand 1973; 194:435-43. 